\title{
ANALYSIS OF EFFECT OF CALCIUM CONTENT ON MACHINABILITY OF ALLOYS TYPE ALSI7MG0.3
}

\author{
Elena Strihavkova \\ J. E. Purkyne University in Usti nad Labem, Czech Republic \\ elena.strihavkova@ujep.cz
}

\begin{abstract}
The choice of aluminum alloy for casting is subject to a number of the basic criteria such as strength, shape, precision, surface quality, weight, corrosion resistance, etc. The structure, and in particular the mechanical, technological and chemical properties of aluminum alloys type Al - Si (silumines) may be affected primarily by modification and addition of the inoculants. The paper deals with the research in the field of new AlSi7Mg0.3 alloys with different calcium content and especially the machinability of the alloy. For experimental purposes an aluminum alloy from the group of hypoeutectic silumin AlSi7Mg0.3 was used. Alloying took place using calcium in the form of AlCa10 alloy. A total of 4 melts were cast. The first without addition of AlCa10 pre-alloy and the other three with graduated calcium, up to $0.1 \%, 0.5 \%$ and $1 \% \mathrm{Ca}$. The specimens thus prepared were subjected to a spectrographic analysis of the chemical composition to confirm the added calcium content. Subsequently, an analysis of the technological properties and especially of the machinability was carried out. In the last part, there were the chips evaluated produced during the machining of the experimentally produced alloys. To measure the chip size, it is possible to determine the sludge effect on the shape and size of the chip, as only certain types of chips are required during processing, namely, which are most suitable for the continuity of the machining process. Another reason for chip analysis was the change of the chip shape in the case of wear of the cutting tool during the cutting process. This topic is currently very topical in view of the high requirements of material parameters, especially in the automotive industry.
\end{abstract}

Keywords: aluminium alloys AlSi7Mg0.3, calcium modification, master alloy AlCa10, machinability.

\section{Introduction}

Aluminum alloys with silicon have a very fast development due to the wide range of applications, they are among the most widely used foundry alloys in terms of volume and most produced aluminium alloys in the nonferrous metal foundry industry. The structure and the related mechanical, technological and chemical properties of the aluminium alloy type Al-Si (silumines) can be influenced mainly by modification and addition of inoculant.

Modification is the process by which a melt is treated with various elements, or their alloys, in order to influence the solidification mechanism of the eutectic. The modifying effect of calcium is not yet fully investigated.

The opinions on Al-Si calcium modification are essentially different. Part of the authors consider calcium to be a modifier, the other part that calcium has a modifying effect as a harmful element, because the calcium modified structure is inferior to that of another element. At a higher calcium content (above 0,14 wt. \%), the intermetallic phase of $\mathrm{CaSi} 2$ and another, yet undetected composition, is formed. These phases disrupt the homogeneity of the structure and reduce the mechanical properties [1]. At the same time, the formation of this phase negates the harmful effect of Si. Without the addition of $\mathrm{Ca}$, it would also not be possible to produce thin walled and complicated castings, since $\mathrm{Ca}$ improves the casting properties, and in particular, curves. The presence of $\mathrm{Ca}$ further reduces the corrosion resistance of foundry alluminum alloys, increasing the solubility of hydrogen in the melt causing the presence of pores in castings [2]. At present, this issue is very topical in view of the high demands of both the qualitative and quantitative parameters, especially in the automotive industry.

Calcium has been used for binding impurities in aluminium alloys in the past, but the results were not stable. Calcium was also designed to improve electrical conductivity in commercial aluminium.

The paper deals with the influence of added AlCa10 master alloy into hypoeutectic silicon AlSi7Mg0.3 mainly due to the technological properties of the new AlSi7Mg0.3Ca alloy. Calcium causes a significant change in the structure of the original $\mathrm{AlSi} 7 \mathrm{Mg} 0.3$ alloy by eliminating eutectic silicon in the form of rods to fibres that appear as round grains in the metallographic section. A machinability test was performed on the investigated alloys, with chip formation.

From the binary diagram of Al-Ca (Fig. 1) the solubility of calcium in aluminium is readable to some extent, it is a hypereutectic alloy. AlCa10 alloy contains eutectic $(\alpha+\mathrm{AlCa} 4)$ and coarse plates of the $\mathrm{Ca} \mathrm{Al} 4$ phase. Metallurgical defects and large pores are also evident in the structure. It can also 
be stated that the AlCa10 master alloy exhibits considerable structural heterogeneity in the CaAl4 phase plate distribution [3].

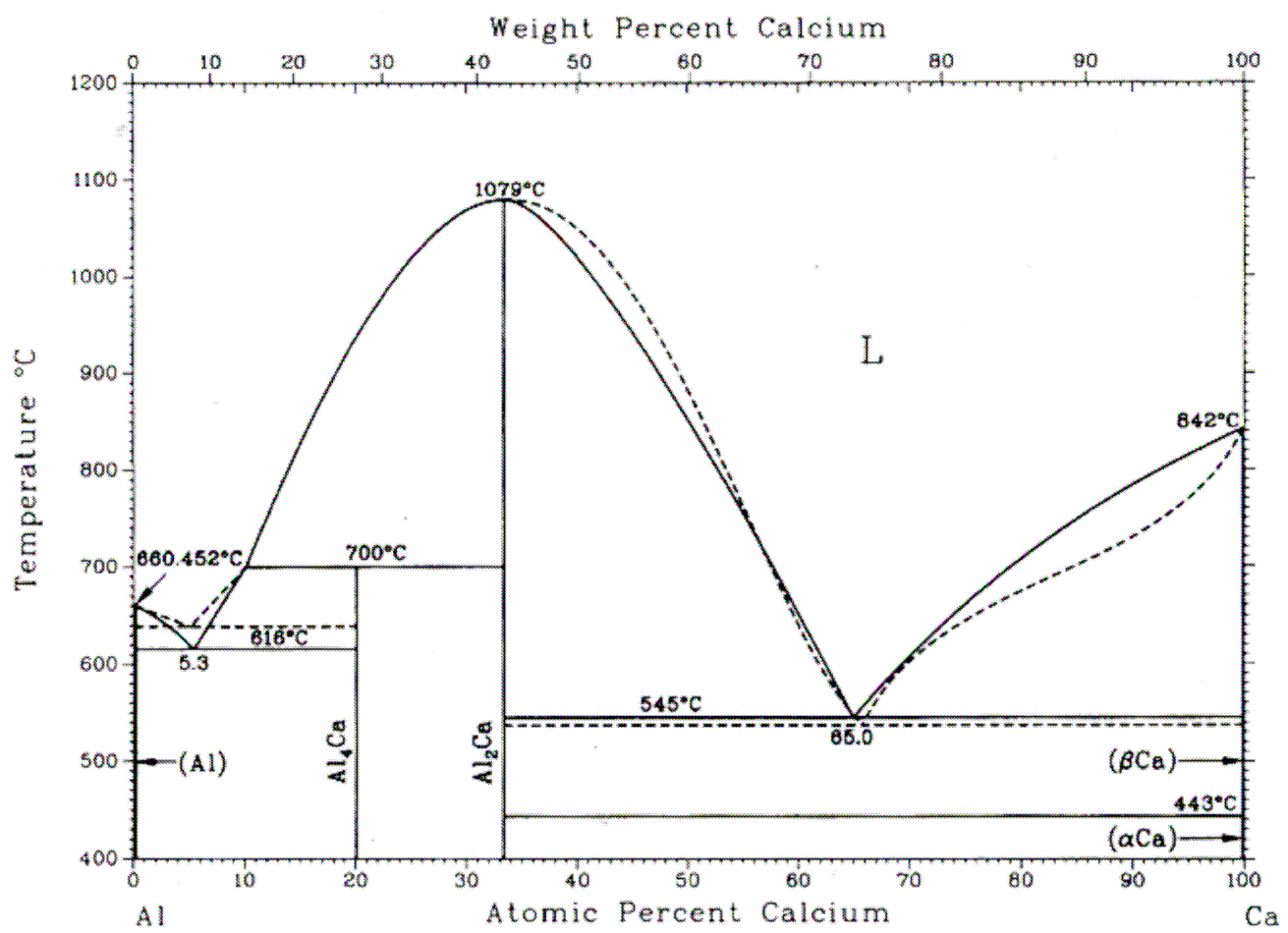

Fig. 1. Binary diagram aluminium - calcium [4]

\section{Preparation of AlSi7Mg0.3 alloy samples with different Ca content}

For experimental purposes an aluminium alloy from the group of hypoeutectic silumines $\mathrm{AlSi} 7 \mathrm{Mg} 0.3$ with the chemical input is listed in Table 1 . Alloying was carried out using calcium in the form of AlCa10 master alloy. A total of 4 heats were cast. First, without addition of AlCa10 master alloy and three others with graded calcium $0,1 \%, 0,5 \%$ and $1 \% \mathrm{Ca}$.

Table 1

Input chemical composition of alloy AlSi7Mg0.3

\begin{tabular}{|c|c|c|c|c|c|c|c|c|c|}
\hline & \multicolumn{8}{|c|}{ Chemical composition in \% by weight } \\
\cline { 2 - 10 } & $\mathrm{Si}$ & $\mathrm{Fe}$ & $\mathrm{Cu}$ & $\mathrm{Mn}$ & $\mathrm{Mg}$ & $\mathrm{Cr}$ & $\mathrm{Ni}$ & $\mathrm{Zn}$ & $\mathrm{Ti}$ \\
\cline { 2 - 10 } Alloy & 7.09 & 0.105 & 0.001 & 0.017 & 0.230 & 0.001 & 0.001 & 0.003 & 0.118 \\
\cline { 2 - 10 } & \multicolumn{8}{|c|}{ Chemical composition in \% by weight } \\
\cline { 2 - 11 } & $\mathrm{B}$ & $\mathrm{Be}$ & $\mathrm{Ca}$ & $\mathrm{Cd}$ & $\mathrm{Ga}$ & $\mathrm{Li}$ & $\mathrm{Na}$ & $\mathrm{V}$ & Aluminium \\
\cline { 2 - 10 } & $<0.0001$ & $<0.0000$ & $<0.0002$ & 0.0036 & 0.0131 & $<0.0000$ & 0.0004 & 0.0031 & $<92.41$ \\
\hline
\end{tabular}

Castings were round bars with a diameter of $20 \mathrm{~mm}$ and a length of $200 \mathrm{~mm}$. The individual melting, refining and alloying processes were performed in an oven at $720^{\circ} \mathrm{C}$, the temperature was scanner with a digital thermometer with an accuracy of $\pm 2{ }^{\circ} \mathrm{C}$. At each melt the melt was treated with the refining salt and wipe was removed from the melt surface. The melt was gravitationally cast into a metal chill preheated to $220^{\circ} \mathrm{C}$. After the casting the test specimen were modified and turning took place in several steps:

1. Drilling the centring pits at both ends of the bars and turning the circumferential surface for further clamping.

2. Extruding the test sticks along the length to a diameter of $15 \mathrm{~mm}$, where the sample was clamped between the chuck and the point fixed in the lathe tail.

3. Turning the test rods to the final shape, removing the centre of the $12 \mathrm{~mm}$ rod sections. 
For cutting the machining conditions were determined to state the effect of the structural change by adding calcium to the chip shape. For machining all castings had the same cutting conditions and one type of cutting inserts [4].

Cutting conditions were determined primarily with respect to the type of the machine and tool used. The tool used was the cutting insert Pramet DCMT070202E-UR, which is shown in Fig. 2 and Table 2. The following conditions were determined based on the machine material and the machine and tool used. Depth of cut $a_{p}=1 \mathrm{~mm}$ and the feed rate per revolution $f=0.12 \mathrm{~mm}$, these conditions were chosen in order to ensure that the plate was fully loaded and the wear was made with respect to the material to be machined. The cutting speed was adjusted to the maximum speed of $n_{\max }\left[\min ^{-1}\right]$, used Emcomat - $14 \mathrm{~s}$.

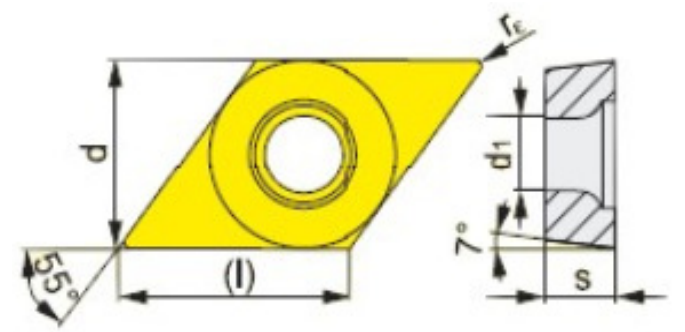

Fig. 2. Cutting insert DCMT070202E-UR [5]

Characteristic of cutting insert DCMT070202E-UR [5]

\begin{tabular}{|c|c|c|c|c|c|c|c|c|}
\hline \multicolumn{4}{|c|}{ Dimensions, mm } & \multicolumn{2}{c|}{ Feed, mm } & \multicolumn{2}{c|}{ Depth of cut, mm } \\
\hline$l$ & $d$ & $d_{1}$ & $s$ & $r_{\varepsilon}$ & $f_{\min }$ & $f_{\max }$ & $a_{\min }$ & $a_{\max }$ \\
\hline 7.8 & 6.350 & 2.8 & 2.38 & 0.2 & 0.05 & 0.12 & 0.2 & 1.0 \\
\hline
\end{tabular}

To determine the final cutting conditions, calculations were made, which were calculated with respect to the optimum tool life. The calculation of the cutting conditions was based on the type of the cutting inserts chosen; the maximum conditions of use were chosen to show the signs of wear relative to the material to be machined and the quantity of the workpiece material to be machined.

Using the maximum speed of the machine, the cutting speeds were adjusted to a cutting speed $v_{c}=226 \mathrm{~m} \cdot \mathrm{min}^{-1}$, at this speed the maximum speed was $n_{\max }=3998.585 \mathrm{~min}^{-1}$. The adjustment of the values was due to the maximum load in order to show the wear [5].

\section{Shape measurement and chip size}

To measure the size and shape of the chips the Olympus SZX 10 light microscope was also used. That is best suited to the smoothness of the machining process. Another reason for the chip analysis was a change in the chip shape in the event of the cutting tool wear during the cutting process.

The shape measurement and the size of the chip are mainly influenced by the temperature, which increases during the working cycle. Higher temperature chips have a significantly smoother character.

Five pieces of chips were removed from each casting type for analysis to determine the chip size and shape.

\section{Shape and chip size in AlSi7MgO.3 alloy with 0 wt. \% Ca}

The first chip measurement was carried out on AlSI7Mg0.3 alloy without the added amount of calcium 0 wt. \% Ca. After machining of all castings five pieces of chips were taken, on which the measurements were made. The appearance of the chips is shown in Fig. 3, in this type of alloy a chip has been formed, which, according to the chip classification, is defined as a chip splintered with a tendency to form clump. The average of the measured values is given in Table 3 .

\section{Shape and chip size in AlSi7MgO.3 alloy with 0.1 wt. \% Ca}

Further chip measurement was performed on AlSi7Mg0.3 alloy with the added amount of calcium 0.1 wt. \% Ca. After machining all castings five pieces of chips were removed again to measure the 
chip size and define the chip shape. The chip shape is shown in Fig. 3, this chip is defined according to the chip classification as a wound chip medium with a predominance of 5-15 turns, and the average of the measured values is given in Table 3 .

\section{Shape and chip size in AlSi7Mg0.3 alloy with 0.5 wt. \% Ca}

Chip measurement on AlSi7Mg0.3 alloy with the added amount of calcium 0.5 wt. \% Ca was performed under the same conditions as in the previous cases. After machining all castings five pieces of chips were removed to measure the chip size and define the chip shape. The chip shape is shown in Fig. 3, this chip is defined by the chip sorting as a short chipped chip with a predominance of 35 turns, and the average of the measured values is given in Table 3.

\section{Shape and chip size in AlSi7Mg0.3 alloy with 1 wt. \% Ca}

The last chip measurement was performed on AlSi7Mg0.3 alloy with the added amount of calcium of $1 \mathrm{wt}$. \% Ca. After machining all castings five pieces of chips were removed to measure the chip size and define the chip shape. The chip shape is shown in Fig. 3, this chip is defined as a coiled mixed chip according to the chip sorting, it is a combination of two types of chips, elementary chips up to three turns and medium chips with a predominance of about 5-12 turns. The average of measured values is in Table 3 .

Table 3

Average chip length for AISi7Mg0.3 alloy with various wt. \% of Ca for 5 measurements

\begin{tabular}{|c|c|}
\hline Alloy & Average chip length, $\boldsymbol{\mu m}$ \\
\hline AlSi7Mg0.3 s 0.0 wt. \% Ca & 358492.526 \\
\hline AlSi7Mg0.3 s 0.1 wt. \% Ca & 127845.392 \\
\hline AlSi7Mg0.3 s 0.5 wt. \% Ca & 6357.696 \\
\hline AlSi7Mg0.3 s 1.0 wt. \% Ca & 73452.394 \\
\hline
\end{tabular}

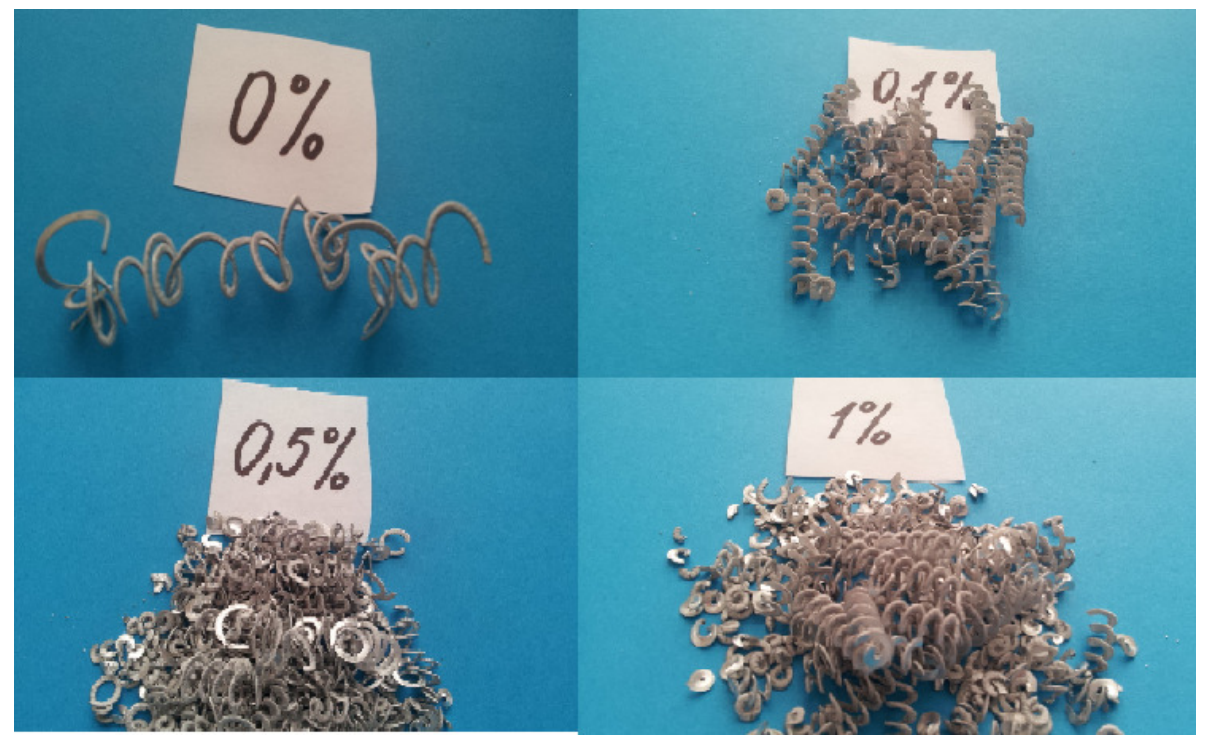

Fig. 3. Shape and chip size in AlSi7Mg0.3 alloy with different content Ca

\section{Results and discussion}

Fig. 4 gives a comparison of the average chip length values for all analysed alloys. The graphs show significant differences in the chip length for individual types of alloys. The worst chip values were measured for the initial AlSi7Mg0.3 alloy, with no added calcium, this is an order of magnitude higher, as evidenced by the photographic documentation. In alloy with a calcium content of $0.1 \mathrm{wt} \%$ the chip length decreases, significantly decreasing in another case, where the calcium content is $0.5 \mathrm{wt} . \%$ and in the latter case with a calcium content of $1 \mathrm{wt} . \%$ the chip length increases. It is clear from the graph and photographic documentation that the addition of calcium has an overall positive 
effect on chip formation and its division. The best chip is produced at $0.5 \mathrm{wt} . \%$ of calcium, where the chip is wound short with 3-5 turns.

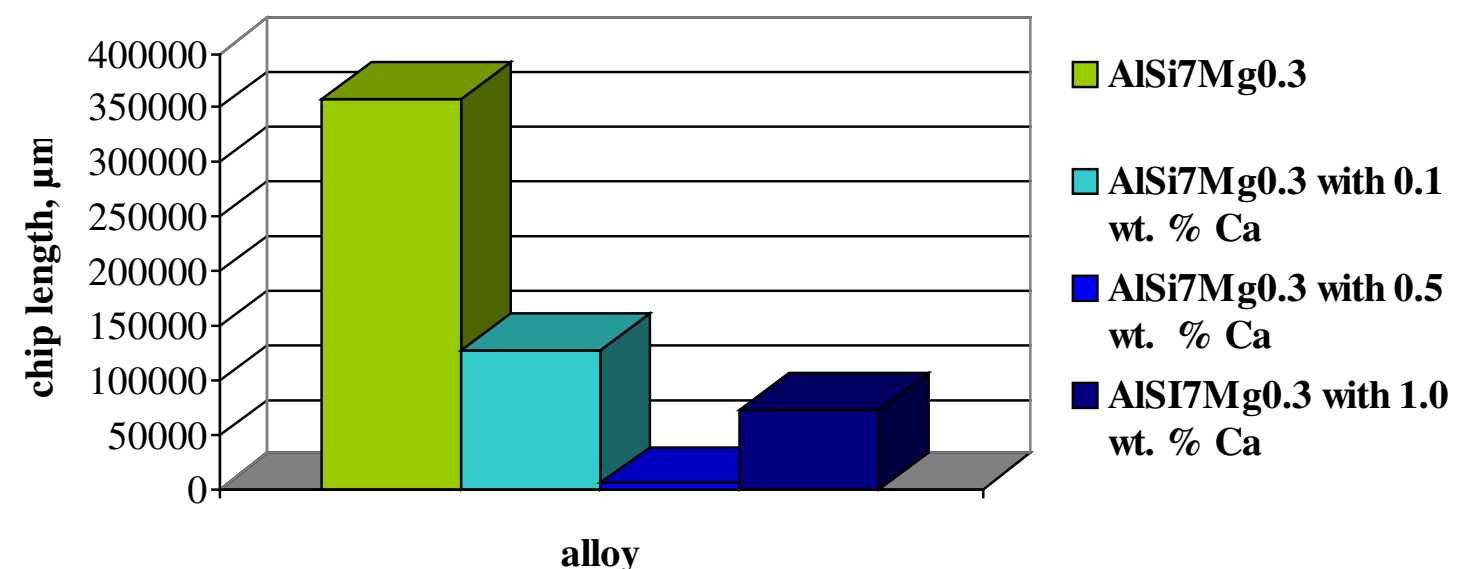

Fig. 4. Comparison of average chip length values for samples from AlSi7Mg0.3 alloy with different calcium content

\section{Conclusions}

A machinability test was performed on the investigated alloys. The test results show a positive effect of calcium on tool wear. Alloys with a calcium content of $0.1 \mathrm{wt} . \%$ and the alloy with $0.5 \mathrm{wt} . \%$ $\mathrm{Ca}$ have shown very good values. There is a change in the morphology of silicon, which appears to be positive for the machining process. The growth was also positively influenced by the calcium content of the alloy. The biggest increase was formed during the machining of the starting alloy, which is probably due to the fact that aluminium alloys tend to have such behaviour. Upon addition of calcium to the alloy, there was a marked reduction in the increase. Another part of the machinability test was the size measurement and chip shape analysis. Chip shape and size measurements were made to determine the effect of calcium on the machining process.

Based on the measurements performed so far, we can state the positive effect of calcium on the given alloy, especially in the amount of 0.1 to $0.5 \mathrm{wt}$. \% Ca.

\section{References}

[1] Bolibruchová D., Tillová E. Zlievarenské zliatiny Al-Si (Al-Si foundry alloys), ŽU v Žiline EDIS, Slovak republic, 2005 (In Slovak).

[2] Wang L., Makhlouf M. Aluminium die casting alloys: alloy composition microstructure and properties - performance relationships. In: International Materials Reviews, Vol. 40, No. 6, 1995. pp. 221-238.

[3] Michna Š., Střihavková E. Legování hliníkových slitin vápníkem, Strojírenská technologie, Vol. 15, No. 2, 2010, pp. 20-23.

[4] MAV. výroba řezných nástrojů a měřidel, [online] [cit. 2014.05.29] Available at: https://katalog.mav.cz/detail.php?id = 86936

[5] Strrihavková E. Analysis of machinability of new AlSi7Mg0.3 alloys with different calcium content, In: Manufacturing Technology, Vol. 18, No.4, 2018, pp. 679-685. 